\title{
WATER EMERGENCE FROM THE LAND REGION AND WATER-SIDEWALL INTERACTIONS IN PROTON EXCHANGE MEMBRANE FUEL CELL GAS CHANNELS WITH MICROGROOVES
}

Mihir M. Shah

Mechanical Engineering, Rochester Institute of Technology, Rochester, New York, USA 14623

Email: $\quad$ mihirshah298@gmail.com

Satish G. Kandlikar (Corresponding author)

Mechanical Engineering and Microsystems Engineering, Rochester Institute of Technology,

Rochester New York, USA - 14623

Telephone No.: $\quad+15854756728$

Email: $\quad$ sgkeme@ $\quad$ rit.edu

Fax No.: $\quad$ + $\quad+15854757710$

\begin{abstract}
Liquid water produced in a Proton Exchange Membrane Fuel Cell (PEMFC) can adversely affect the fuel cell performance in two ways: (a) reduction in surface area available for reactant transport at the channel-gas diffusion layer (GDL) interface, and (b) increase in two-
\end{abstract}


phase pressure drop in channels leading to flow maldistribution and increased pumping power. Further, the channels blocked by water reduce reactant availability at reaction sites. Most of the earlier water transport studies were focused on water droplet formation on the gas diffusion layer (GDL) in the channel and its removal from the gas flow without considering the sidewall interactions. In an actual fuel cell, water under the land emerges in the channel and fills the corner, drawing in additional water from the GDL surface. The present work explores water droplet-sidewall interactions and the transport of water from the corner region. Transverse micro-grooves are introduced on the sidewalls and their effect on water removal from the corner region, flow patterns, area coverage ratio and pressure drop are investigated. The micro-grooves are also seen to introduce a wetting regime that facilitates removal of water at the channel exit without causing blockage at the manifold region.

\section{Keywords}

Channel corner, Grooved sidewall, Channel land, Water management, Pressure drop

\section{Introduction and Literature Review}

Reactant gas supply channels play an important role in the working of PEM fuel cells. The gas channels bring the reactants to the GDL surface for transport to the reaction sites, and carry the product water out of the cell. Water emerging from the GDL surface into the channel has been studied extensively in literature, but the water emerging from under the lands in the channel corners has received very little attention in literature. 
Previous work done by Kumbur et al., [1], Lu et al. [2], Cho et al. [3] and Polverino et al. [4] studied water being generated at the channel center along the flow axis. When water is injected at the channel center, the emerged droplet shape fluctuates with change in air flow rate. The droplet instability was found to be dependent on droplet size, channel size and the hydrophobicity of the GDL. A droplet is shown to grow and be removed due to air flow or transition into a film or a slug, which completely blocks the channel. However, these studies were limited to droplet-GDL interaction only and did not take into account the sidewall interactions.

Films are formed when a droplet grows in size and starts interacting with the sidewall. In one of the few studies on droplet-sidewall interactions, Theodorakakos et al. [5] in 2006 established that droplets are removed from the channel at slower velocities if they are also touching the sidewall and top wall. The reduced speed increases the resistance to flow of reactant gases and increases the pressure drop. Rath and Kandlikar [6] investigated the fundamental interactions between the water droplet and the sidewall and showed that the sidewall angle strongly impacts the water behavior. In 2012, Gopalan and Kandlikar [7] introduced air flow into the system investigated by Rath and Kandlikar. Gopalan and Kandlikar [7] [8] also presented extensive work with trapezoidal channel angles and water droplet injection at channel center. They established that the $50^{\circ}$ trapezoidal angle was the most suitable to avoid channel crosssection filling, which leads to slug flow and hence causes increased pressure drop.

Most of the previous research in this area has been focused on water droplet emerging at the channel center, neglecting the presence of water in channel corners and under the land. Schneider et al. $[9,10]$ have done extensive in-situ work using segmented fuel cell flow fields. 
They measured local current densities in different parts of the flow-field and channel. Current density was found to be limited in the land region at higher voltages due to mass transport losses indicating difficulty in water removal from the GDL in the lateral direction underneath the land area. These findings are crucial and show that water generation under the land affects cell performance directly and water management in that cell region needs attention. Recently, Cheah et al. [11] analyzed spherical droplets transitioning into films and slugs. They discussed the interactions at a corner with Teflon coated sidewalls. Water was injected upstream and the shearing and ejection of water droplets were studied. They observed that droplets are ejected from the corner at a very high Reynolds number while films are shed at lower values of Reynolds number, suggesting formation of films can be beneficial in case of corner water droplet emergence.

Fundamental studies to identify corner droplet-sidewall interaction were conducted by Gopalan et al. [7] in 2012. They investigated effects of corner droplet injection in an ex-situ PEMFC channel. Figure 1 shows the locations for droplet injection in a trapezoidal channel. It was found that when water was injected into the channel about $0.5 \mathrm{~mm}$ from the sidewall, the channel was filled with water for all air flow rates. The Concus-Finn [6][12] condition used for predicting droplet behavior between two surfaces fails to predict the behavior for corner droplet due to oscillatory nature of droplet interface.

Lee et al. [13] conducted experiments with rectangular channels and water injection at channel corners. They evaluated the effects of GDL wetting behavior on the droplet movement and pressure drop. A hydrophilic GDL caused the droplet to avoid corner filling and forced it to avoid sidewall contact. Effect of the sidewalls' wettability was suggested to have no effect on 
water behavior in their work. The effect of hydrophilic, hydrophobic and uncoated channel sidewalls with hydrophobic GDL on two-phase pressure drop and water flow patterns was discussed by Lu et al. [2] and no clear trend regarding the channel wettability that causes low two-phase pressure drop could be identified.

Droplet interactions on a grooved surface have been investigated in literature [14-21] which discussed selective water droplet drainage or retention. Sommers et al. [14] compared droplet velocity for different liquids on plain and grooved surfaces. Droplets had a higher velocity on grooved surfaces than over a plain surface. Chen et al. [21] concluded that surface roughness amplifies the water repellency of surfaces. Rahman et al.[15] discussed the effect of droplet shape on water drainage from a grooved surface and the effect of geometrical parameters like groove depth, pillar width and a factor known as solid fraction, $=\mathrm{W}_{\mathrm{P}} /\left(\mathrm{W}_{\mathrm{P}}+\mathrm{D}_{\mathrm{G}}\right)$, where $\mathrm{W}_{\mathrm{P}}$ is groove pillar width and $\mathrm{D}_{\mathrm{G}}$ is groove depth. They indicated that in order to easily remove water from a grooved surface, the surface should be designed such that the groove width to pillar width ratio is $>0.2$ (reciprocal of Scaling Factor developed by Nosonovsky et al.[18]) and at the same time, the pillar width should be limited as the solid fraction increases both strength of droplet pinning and sliding angle for removal.

Gopalan et al. [22] studied different grooved surfaces and their static wetting behavior. This included the Cassie-Baxter, Wenzel and metastable [23-25] wetting regimes. In this work, rectangular grooves on PEMFC gas channel sidewalls were proposed. These grooves were targeted at enhancing removal of water injected at the channel corner or emerging from under the land. Further investigation of the grooved surfaces for directional wettability included a study by Wang et al. [26], who presented a detailed discussion about the individual and combined wetting 
due to micro-grooves having Cassie and Wenzel roughness. They noted that the wetting regimes observed under static conditions may not hold true during dynamic water flow over the grooves and that is when it tends to possess both wetting regimes simultaneously. It was established in case of metallic grooved surfaces that drops in Wenzel wetting state are more elongated (films) than Cassie-Baxter wetting state under dynamic conditions. These findings confirmed to a certain extent that grooved sidewalls can help improve water management in a PEMFC gas channel.

The slugs formed in a PEMFC channel and its dynamics are affected by the gas bypassing through the GDL. Slugs can divert the gas flow through the gas diffusion layer (GDL) beneath the channel ribs to adjacent channels in a channel flow field with multiple channels. This study is limited to a single channel. This flow diversion can cause slug motion to slow down or come to a halt.[37][[38] Ye et al. [37] explain in their paper that the gas pressure drop required to overcome slugs is independent of the slug volume. In this work, different water features have been observed along with slugs. For the cases with slugs, the gas bypass will affect the pressure drop results, but its effect is expected to be negligible.

\section{Objectives of the Present Work}

Considerable work has been done on single water droplet behavior in a cell channel; however, not enough studies include the effect of sidewall interactions. Earlier work on droplet behavior on grooved surfaces by Gopalan and Kandlikar [22] show that water droplet movement and droplet shape is significantly affected by the presence of grooves. In this study, grooves on the sidewalls are considered for water droplet movement away from the channel corner. The implementation of grooved sidewalls targets at promoting film flow behavior while 
avoiding channel cross-section blockage by slugs. At the same time, these water films are expected to cling more to the channel sidewalls and top wall rather than to the GDL surface. An experimental study is undertaken to investigate the effect of the sidewall grooves on water removal from the corner region and its influence on the flow patterns, pressure drop, area coverage ratio of water features on the GDL, and water removal from the exit manifold region. This will ultimately improve gas transport through the GDL and reduce oxygen transport resistance by providing efficient drainage pathways for water formed under the land regions.

\section{Experimental}

Experiments in this work focused primarily on water droplets injected in the channel close to the channel sidewall promoting corner filling. The basic setup, its components and assembly are discussed in Section 2.1, while the experimental procedure is presented in Section 2.2.

\subsection{Setup}

The setup consists of four different plates made from Lexan that form the channel walls and an air manifold at the back as shown. The air manifold is a square of $19 \times 19 \mathrm{~mm}(0.75 \times$ 0.75 inches) size. The channel plates are $101.6 \mathrm{~mm}$ (4 inches) long and are bolted together to form a trapezoidal channel with $50^{\circ}$ sidewall angles. The height of the channel is $3 \mathrm{~mm}$ and the top and bottom sides are $3 \mathrm{~mm}$ and $8 \mathrm{~mm}$ respectively. The larger channel size as compared to a fuel cell channel is chosen to facilitate visual observation and study the sidewall interactions and drainage mechanisms. A gas diffusion layer forms the base to replicate the channel in an actual fuel cell. A baseline MRC-105 Gas Diffusion Layer (GDL) was used for the tests in this 
work. A PTFE gasket was placed between the base and sidewall plates to ensure proper sealing of the channel. The grooved sidewall replaces the left channel plate for the first phase of testing and then the right channel plate in later experimental phases. The grooves are $200 \mu \mathrm{m}$ wide and $101 \mu \mathrm{m}$ deep having a rectangular cross-section. There are two water injection sites, one in the center and one in the left corner. Figure 1 (a) shows the schematic of the channel.

There are two test setup configurations used in this work. The first test setup, shown in Figure 1 (b), is designated as Configuration $\mathrm{C} 1$ and is designed to identify the channel crosssectional filling and non-filling behavior at the channel exit. The water is injected toward the exit of the channel and the water droplet emerging from the end is observed. The second test setup, designated as Configuration $\mathrm{C} 2$, is designed for top view visualization along the entire channel when water is injected upstream and the transition from droplet generation to film to slug can be observed. The water is injected in the middle, closer to the air entry, and its expansion in the channel is observed. Figures 1 (b) and (c) show the schematics of test setup configurations $\mathrm{C} 1$ and $\mathrm{C} 2$ specifying the difference between water inlet locations respectively. Testing was done on these configurations with and without Teflon coatings on the grooved surfaces as described below.

Configuration $\mathrm{C} 1$ (Water injection $12 \mathrm{~mm}$ upstream from the channel exit)), Figure 1(b)

C1.1. Plain sidewall

C1.2. Single Grooved Sidewall (One channel wall grooved, other non-grooved)

a. Without Teflon

b. With Teflon (On groove land tops only)

C1.3. Both Grooved Sidewalls (Both channel walls have grooves) 
a. Without Teflon

Configuration C2 (Water injection - $76 \mathrm{~mm}$ away from channel exit), Figure 1(c)

C2.1. Plain sidewall

C2.2. Single Grooved Sidewall (One channel wall grooved, other non-grooved)

a. Without Teflon

C2.3. Both Grooved Sidewalls (Both channel walls have grooves)

a. Without Teflon

Configuration $\mathrm{C} 1$ is intended to obtain the local information as a droplet emerges to study the filling characteristics, local pressure drop and its variation across a single droplet, and interactions with the opposite wall. Configuration $\mathrm{C} 2$ is designed to study flow patterns developed upstream, middle section, and downstream locations of the channel. In case of local dropletsidewall (C1) approach, side view has been captured with a high speed camera and local pressure drop across the droplet is measured. Data is recorded in the form of time dependent $\Delta \mathrm{P}$ signatures for each air flow rate tested.

A Keyence VHX-Digital Microscope with a video camera and a $\mathrm{X}$ to 50X zoom lens is used. A 30X zoom and a frame rate of $28 \mathrm{fps}$ are employed for recording the images and videos. An external light source is used to illuminate the area of focus. Zero-grade pressurized air is used from a gas bottle. It is supplied through an Omega rotameter and a digital air flow meter loop. The rotameter knob is used to control the air flow and the digital air flow meter gives direct continuous reading of the air flow rate being used.

\subsection{Experimental Procedure}


Leak test was conducted after each assembly of setup to detect and mitigate leakage using a gas leak testing fluid. The setup was conditioned by single phase flow in the channel for 15 minutes prior to testing. Two slugs were allowed to form and eject before the first test in a test matrix was started to ensure that flow patterns are established and are repeatable. Water flow rate of $0.05 \mathrm{ml} / \mathrm{min}$ was used. It corresponds to a current density of $0.3 \mathrm{~A} / \mathrm{cm}^{2}$. The experiments conducted by previous researchers indicate that change in water flow rate affects only the time duration over which flow patterns are formed and removed from the channel (so long as multiple droplets or droplet merger do not occur), and not affect pressure drop in a single channel $[29,30]$. Thus, effect of change in water flow rates is negligible on test results. Air flow velocities were chosen based on the standard fuel cell operating conditions [7]. The Reynolds Number (Re) was varied from 39-390 out of which results from $\operatorname{Re}=40$ to 237 are presented. At $\operatorname{Re}$ beyond a certain value, the air superficial velocity is high enough and causes the water in the channel to be in the mist or droplet regime only and slug formation is not observed [31]. However the problem of channel blockage due to slugs has been identified and hence investigations need to be made for low air velocities that cause formation of slugs. Table 1 below shows the air flow velocities used and the corresponding Reynolds Number.

\section{Results and Discussions}

For each channel design, results from the visualization study were obtained in conjunction with continuous pressure drop measurements. The videos were time-stamped to correlate with the pressure drop measurements. Previous research [7] had identified droplet-sidewall interaction for different channel configurations. It was established that trapezoidal channel geometry with $50^{\circ}$ as the angle for the trapezoid is highly suitable for PEMFC channel configuration with two- 
phase pressure drop, water management and manufacturing considerations [7]. Adopting this geometry to further investigate the water removal characteristics, grooved surface modifications and coatings were employed on $50^{\circ}$ trapezoidal channels.

\subsection{Pressure Drop Validations and Visual Results Correlations for Plain Sidewall Channels (Water injection near channel exit, $\mathbf{C 1}$ )}

A plain sidewall channel having a trapezoidal cross-section with an angle of $50^{\circ}$ is subjected to a water droplet entering the channel from the channel corner near the sidewall. For low air flow rates from 0.1 to $0.5 \mathrm{~m} / \mathrm{s}$, there is no blockage as slugs are formed and exit the channel. Air flow rates higher than $0.5 \mathrm{~m} / \mathrm{s}$ have more pronounced effect on droplet removal characteristics. As the slugs are formed, they start getting stuck near the channel exit and the pressure drop fluctuates as shown in Figure 2.

Figure 2 shows a pressure drop curve for a time duration of 600 seconds for air velocity of $0.5 \mathrm{~m} / \mathrm{s}$. Droplet-plain sidewall interaction imaging has been categorized into different phases and has been correlated to different regions of the pressure drop curve.

In Figure 2, Phase 1 shows a droplet entering the channel at the corner near the sidewall. Phase 2 shows its consequent growth along the GDL and eventually touching the top wall and right opposite top corner. Pressure drop rises steadily as this happens. The water droplet then completely blocks the channel area and the pressure drop peak is seen in Phase 3 . The first slug thus formed exits the channel. As water is continuously injected in the channel, water rises again to form the droplet as shown in Phase 4. Water keeps ejecting from the channel in small drops. Three repeated curves after about 210 seconds are seen as the phenomenon repeats itself in Phase 
5. Preliminary observations indicated this blockage occurred when the second slug was formed as the first slug exited the channel.

Results below show that for low air flow rates, water droplets generated at the channel corner (near the sidewall) tend to exit the channel once a slug is formed in the direction of air flow. However at higher air flow rates, this behavior changes and we see droplet sticking behavior as explained below. Figures 3 (a) shows pressure drop plots for low air flow velocities against time [(1) $0.18 \mathrm{~m} / \mathrm{s}$, and (2) $0.36 \mathrm{~m} / \mathrm{s}$ ] for a plain sidewalls channel. For low air velocities between 0.1 to $0.5 \mathrm{~m} / \mathrm{s}$ slugs, are formed and ejected from the channel. These peaks and drops on the pressure drop plot are repeatable and do not show any recurring fluctuations. The visualization results also illustrate that there is no pinning or blockage at low air flow velocities. However, for air flow velocities above $0.5 \mathrm{~m} / \mathrm{s}$, as seen in pressure drop plots in Figure 3 (b), the droplet behavior changes.

For higher air flow velocities, the emerging water droplet does not get enough time to attach and carry the films already present in the channel. This causes accumulation of water near the channel exit. Figure 3 (b) shows pressure drop plots against time for two air velocities of (1) 0.7 and (2) $0.8 \mathrm{~m} / \mathrm{s}$. The droplet-sidewall interaction is very similar to that observed for an air velocity of $0.5 \mathrm{~m} / \mathrm{s}$ (Figure 2). Arrows on the plots indicate the formation and drainage of first slug after the test was started. After the first slug ejects, the second slug blocks the channel exit at about 1500 seconds on the plot in Figure 3 (a1). The image sequence for the pressure drop behavior in Figure 3 (a1) is shown in Figure 4 (a). Figure 4 shows the trapezoidal plain channel cross-section and a droplet emerged from channel corner and the consecutive sequence of images as the droplet interacts with the channel wall. At $0.89 \mathrm{~m} / \mathrm{s}$, the velocity is high and hence after 
the first slug exits, it takes more time for the other slug to be formed which blocks the channel at about 450 seconds into the test shown on the plot in Figure 3 (b2). The images in Figure 4 below show the behavior of the droplet during and after the first slug is ejected from the channel for air (a) First Slug Formation and Removal for Air Velocities $>0.5 \mathrm{~m} / \mathrm{s}$. Time stamps on both Figures 4 (a) and 4 (b) images are from the pressure drop plot in Figure 3 (b). Figure 4 (a) shows the formation of the first slug and the residual water feature after the first slug is ejected. It is clear from the images that a film is formed along the sidewall and it grows in size because the water keeps entering the channel from the same corner. In the last image of Figure 4 (a), it is observed that the water starts blocking the channel area again. In the sequence shown in Figure 4 (b), the droplet-sidewall interaction is continued. At 1622 s, the second slug completes formation showing a peak in pressure drop in Figure 3 (b1) and partial ejection begins illustrating the fall of the pressure drop curve after that (1670 s). At $1732 \mathrm{~s}$, the slug is still blocking the channel cross section causing the pressure drop irregularity. The behavior of water droplets in a fuel cell channel when the droplet is generated at the corner are different compared to when the droplet is generated at the center of the channel.

\subsection{Sidewall Grooves}

In order to address the issue of channel blocking due to water features at higher velocities, sidewalls on grooves were proposed by Gopalan et al [22] as mentioned earlier. These groovedsidewalls were used to improve water drainage characteristics and the results are discussed in this section.

Traditionally, the GDL has been impregnated with PTFE to make it hydrophobic and channel walls are made hydrophilic. Hence, the grooves were designed and manufactured using a 
Scaling Factor(Pillar width to Groove width) [18] of 1.5 (S > 0.2) for promoting water drainage behavior by Wenzel wetting [8]. This Scaling Factor represents Wenzel [25] mode of wetting, meaning water filling the grooves. This design facilitates water transport to the top wall of the channel and improves the water removal process.

The contact angles for all surfaces tested were measured using a VCA Optima contact angle measurement device. The sessile droplet method was used to measure and characterize the contact angles.

Static contact angles were measured using the VCA Optima and have been listed in Table 2 for different surfaces used for studying droplet-channel sidewall interactions. This table also gives a comparison of static contact angles between the plain sidewalls tested in Section 3.1. This establishes the baseline performance and compares it to the grooved sidewall in terms of contact angles.

\subsection{Effect of Sidewall Grooves on Water Accumulation}

In case of water eruption at channel corner, the behavior of plain sidewalls as the baseline channel has been established in Section 3.1. The grooved sidewall setups are tested for dropletsidewall interactions and the results are compared to the baseline test setup in this section. An air velocity of $0.5 \mathrm{~m} / \mathrm{s}$ corresponds to a current density of $0.3 \mathrm{~A} / \mathrm{cm}^{2}$ for the given channel dimensions. Figure 5 shows the droplet sidewall interactions for plain channels (Figure 5 (a)), one grooved sidewall and one plain sidewall channel (Figure 5 (b)) and when both channel sidewalls are grooved (Figure 5 (c)). The first image in every case shows the water droplet in a channel when it is about to grow into a slug after touching the sidewall opposite to the wall near 
which it was injected, and the second image shows the channel area just after the slug is ejected. Figure 1 (a) shows the dry channel area with different dimensions and channel cross-sectional area of the channel used in this work. Figure 5 (d) shows an illustration when the water film is occupying the same channel cross-section. It illustrates the calculation of the water-occupied area in the channel. In Figure 5(d) water is occupying $86 \%$ area of the channel. This quantity will be used to compare performance of different sidewalls and their droplet-interaction. The channel cross-sectional area that is occupied by water after one slug is ejected is calculated from the images and occupies $15.6 \mathrm{~mm}^{2}$, which is $90.3 \%$ of channel cross-sectional area for plain channel. The pressure drop after the slug ejects is $650 \mathrm{~Pa}$. For one grooved sidewall channel, cross-sectional area covered after slug ejection is about $9.51 \mathrm{~mm}^{2}(55.13 \%$ of channel crosssectional area) and pressure drop of $500 \mathrm{~Pa}$.

Figure 6 shows pressure drop plots for the plain and one grooved sidewall channel designs for the air velocity of $0.5 \mathrm{~m} / \mathrm{s}$. The duration of pressure drop measurements is about 600 to $700 \mathrm{~s}$ which vary with channel design. Figure 6 (a1) shows the pressure drop curve for a plain sidewall channel. The pressure drop curve shows that around 150 seconds later the first peak in the curve ends and only fluctuations remain. This is indicative of the water behavior in the channel. It illustrates that the slug is ejected at this point in time, yet it does not completely clear the channel cross section and residuals are left in the form of films and eventually forms a slug (Figure 5 (a)). Small amounts of water keep ejecting from the slug sitting at the channel exit in the form of droplets. This causes the constant change in the pressure drop signal.

If the pressure drop signature is observed in Figure 6 (a2), it is evident that after the first slug exits the channel (2800 s), the pressure drop peak stabilizes. When the signal again shows a 
peak, there are fluctuations at the same pressure drop level. It indicates water getting stuck at the channel exit with a very high rate of droplet fluctuation or movement. The fluctuations have been marked by a red circle on the pressure drop plot in Figure 6 (a2) and it indicates the slug blockage. The image sequence from Figure 5 (b) illustrates this droplet behavior. Figure 6(b) shows the droplet-channel sidewall interaction for the channel with a left grooved sidewall and a right plain sidewall. The time stamps in Figure 6 (b) and (c) are corresponding to the time scale on the pressure drop plot in Figure 6 (a2) and Figure 6 (a3) respectively. After ejection of the first slug, the grooves on the left sidewall are filled with water and the water emerging in the channel starts treating the grooved sidewall as a plain sidewall. This leads to channel crosssectional filling and blockage.

The sequence in Figure 6 (c) shows images of the droplet after the first slug exits the channel ( 420 s). It can be seen that due to the water repellant effect of Teflon, the consecutive slug that is formed in the channel is also ejected at the end of the sequence $(\sim 658 \mathrm{~s})$. It is clear from the images in Figure 6 (c) that the water feature does not completely clear the channel. However, the slug is able to completely exit the channel and thus resistance to flow of air through the channel is eliminated to a certain extent. Figure 6 (a3) shows that the pressure drop fluctuations have been eliminated with the dotted red circle. However channel cross-sectional filling still can be observed although there is no slug pinning and no complete blockage to air flow. The cross-sectional channel area occupied by water is about $13.23 \mathrm{~mm}^{2}$ which is about 76.7 $\%$ of the channel area. The pressure drop however remained around $550 \mathrm{~Pa}$ after slug ejection. Results from this section show one to one comparison of all the four types of sidewalls that were engineered and tested in this work. Pressure drop signature from plain sidewall channel (Figure 6 (a1)) indicates unstable pressure drop and fluctuating water feature behavior. This led to the 
development of channel sidewall with grooves. These grooves help the fluctuation behavior by drainage of water droplets along the grooves and leaving the gas diffusion layer open for reactant transfer as it relates to a real fuel cell. The pressure drop signature in Figure 6 (a2) also indicates the fluctuation of water droplet beyond the first slug exit. Application of Teflon to the groove tops help avoid channel blocking by slugs as seen in Figure 6(a3). However, in order to make this solution more feasible grooves are produced on both sidewalls (Figure 6 (a4)) and the channel is tested. The results are discussed in more detail in the following section.

\subsection{Introduction and Effects of Both Grooved Sidewall Channels}

The channel design thus tested and presented in this section is a channel having grooves on both sidewalls (Configuration C1.3). As it can be seen in Figure 6 (a4), the slug ejection process and droplet-sidewall interaction for both grooved sidewall channel is very similar to the channel having grooves on one sidewall except the fact that the ejection process for both grooved sidewalls channel is faster and leaves less residual water in the channel cross sectional area. Figure 6 (a4) shows pressure drop plot against time for a test of channel having both grooved sidewalls at an air velocity of $0.5 \mathrm{~m} / \mathrm{s}$ and constant water injection rate of $0.05 \mathrm{ml} / \mathrm{min}$. Figure 6 (a4) shows peaks in pressure drop representing slugs formed and ejected continuously. The second channel wall having grooves helps enhancing the water drainage behavior. It increases the hydrophilicity of the channel overall, causing the water to be associated more with the channel walls compared to the base making the surface energy transfer from the base-sidewall interface to sidewall-sidewall interface [5]. The slug ejection process became repeatable for this channel design. The important consideration for this design was how it performs after the first slug is ejected. As it can be seen in Figure 6 (a4), there are continuous peaks and drops in the 
pressure drop indicating non-accumulation and quick removal of water slugs as they are formed. The second grooved wall aids in the removal of water features as air flow velocities increase and only water residuals are absorbed by the grooves. This avoids formation of significantly large slugs or films that would cause accumulation and lead to blockage. The visuals shown in Figure 5 (c) are thus repeated slug after slug and thus the new channel design proposed overcomes the channel end water accumulation and blockage problems. This design with two grooved sidewalls is thus proposed to be adopted in order to eliminate channel end pinning and water accumulation. Therefore, this is the channel that will be compared with the plain sidewalls channel in the sections that follow. The issues observed in channels that have one grooved sidewall have been overcome in this channel design and it is a more feasible solution with manufacturing considerations taken into account. The cross-sectional channel area occupied by water for both grooved sidewalls channel is about $5.71 \mathrm{~mm}^{2}$ which is about $33.10 \%$ of channel cross-sectional area after the slug ejection process is complete. This reduction in blockage is remarkable from about $90 \%$ blockage for baseline channels. The pressure drop after slug ejection is around 520 $\mathrm{Pa}$.

\subsection{Effect of Water Injection Upstream (Configuration C2)}

In an actual fuel cell channel and flow field, water is produced along the entire length of the channel and not just near the exit. The issue of water accumulation and blockage is identified and studied near the channel exit as it also signifies other issues such as droplet pinning. However, over the years, fuel cell channels have been studied for flow patterns along the entire length of the channel at different air and water flow velocities. 
As the previous sections have shown the use of grooved sidewalls for improving drainage characteristics and thus avoid water accumulation, the effect of water features upstream the channel with these channel designs is studied and presented here. The flow rates that were used for these experiments were kept the same as in the case of experiments in Configuration $\mathrm{C} 1$. Figure 7 (a) shows the plots of pressure drop of the two channel designs: Fig. 7 (a1) plain or nongrooved channels and Fig. 7 (a2) channels with grooves on both sidewalls at the air velocity of $0.5 \mathrm{~m} / \mathrm{s}$ at constant flow rate of $0.05 \mathrm{ml} / \mathrm{min}$. The visualization for these experiments was done using the same high speed camera (Keyence VHX-Digital Microscope) as in C1. The results show distinct difference in behaviors with the droplet entry, formation of slug and ejection process for the two channel designs. For the plain or non-grooved sidewalls channel, the injected droplet converts to a film which, after coming in contact with the opposite sidewall, gets converted in a slug. This slug travels at a very high velocity for a small distance and then stays at the same location for 31 seconds. This sequence and shapes of the water features are illustrated in Figure 7 (b-). Similar studies were carried out by Cheah et al. [11] and their results showed films being formed in channels coated with Teflon as against slugs in plain (non-Teflon) channels. In their work, square acrylic channels were investigated, with and without Teflon coating [11]. In Figure 7(b) (1) and (2), the red box shows the channel area with sidewalls, GDL base along with the water features produced and its comparative dimension (size) with the channel. It also shows the time taken for the transitions to happen from $0-40$ seconds. For the new channel design that has been proposed in prior sections $(2.1,2.2)$ with grooves on both sidewalls, the droplet formed in the channel near the point of injection forms a film that travels along the channel wall grooves. The film formed keeps growing along the grooved sidewall and ultimately grows in width near the channel end and then exits the channel. 
Figure 8 shows peak pressure drop values which vary with superficial air velocity. Figure 8 (a) shows peak pressure drops for channel filling identification or setup $\mathrm{C} 1$ and Figure 8 (b) shows peak pressure drops for flow pattern observation setup C2. It can be seen that peak pressure drops in the case of channels with both grooved sidewalls are higher than plain sidewalls and those values are also more regulated than that of single grooved channel sidewall for configuration $\mathrm{C} 1$ as shown in Figure 8 (a). For low air superficial velocities below $0.5 \mathrm{~m} / \mathrm{s}$ the pressure drop values are close to each other for all designs and for air velocities greater than $0.5 \mathrm{~m} / \mathrm{s}$, the values differ by a significant margin.

Figure 8 (b) shows the peak pressure drops for all three channel designs (C2.1-3), for the second experimental setup configuration $\mathrm{C} 2$. It can be seen that the peak pressure drop variation is within the same range as that of configuration $\mathrm{C} 1$ as shown in Figure 8 (a). Also, the set up with two grooved sidewalls channel (C2.3 a) shows least peak pressure drop in all but one data points. This indicates reduced slug blockage and easy removal of water generated in the form of elongated films. When Figure 8 (a) and (b) are compared, we can observe the peak pressure drop trends. It is clear that peak pressure drop is the lowest $(0.7-0.9 \mathrm{kPa})$ out of all three channel designs in the configuration $\mathrm{C} 2$ (Figure 8 (b)) while it is the highest $(0.95-1.105 \mathrm{kPa}$ ) for all but one data points in case of configuration $\mathrm{C} 1$ (Figure 8 (a)) for the channel design with both grooved sidewalls. It was observed in most cases for C2.2 (a) that water film moves very slowly once formed upstream and its motion is very quick as it reaches near the channel exit, just before it is ejected.

\section{Analysis and Quantification of Grooved Sidewalls}

\subsection{Analytical verification of groove geometry and shape}


The contact angle of any rough surface determines the energy variation of the water droplet moving over it. Due to difference in contact angle of water droplet on two different surfaces, there is an energy gradient between the two contacting surfaces - grooved sidewall and gas diffusion layer. The energy $(\Delta \mathrm{E})$ of the droplet in contact with the grooved surface needs to be negative for the droplet to keep moving along the grooved sidewall. The energy gradient is governed by solid fraction of a grooved surface $\left(\phi_{\mathrm{s}}\right)$. If $\Delta \mathrm{E}>0$, the droplet movement on grooves will not be continuous and will cause water droplets to not move along the grooves and in effect make them stay on the gas diffusion layer and accumulate over time before they are blown away by air. In this study, design and implementation of grooves that possess $\Delta \mathrm{E}<0$ for quick movement of droplets over grooves are desired. Analysis below correlates contact angle of grooved surface to energy gradient. As described and mentioned by de Gennes et al. [32], for a rough or grooved substrate, the contact angle produced by a liquid is different than actual and hence is denoted as apparent contact angle $\theta^{*}$. It is given by

$\operatorname{Cos} \theta^{*}=1-\phi_{S}+\phi_{S} \operatorname{Cos} \theta_{E}$

From Young's equation [22,33],

$\operatorname{Cos} \theta_{E}=\frac{\gamma_{S V}-\gamma_{S L}}{\gamma_{L V}}$

where $\phi_{\mathrm{s}}$ - Solid fraction (ratio of total groove-top area to total solid area of grooved or textured surface), $\theta_{\mathrm{E}}$ - Contact angle of the material, and $\gamma$ - Surface tension (SV-Between Solid and Vapor phases, SL- Solid and Liquid phases, LV- Liquid and Vapor phases).

For a droplet advancing on the grooves as it advances on each isle or pillar, let the advancing distance be ' $\mathrm{dx}$ '. This distance ' $\mathrm{dx}$ ' changes for every air flow velocity, and hence energy 
gradient keeps changing, initiating droplet movements. The wet surface area is 'r.dx' where ' $r$ ' is surface roughness. When the droplet travels along the direction of air flow, it leaves the previously occupied area partially dry and wet. The energy variation of a droplet on a grooved surface with roughness ' $r$ ' is given by:

$\Delta \mathrm{E}=\left(\mathrm{r}-\phi_{S}\right) \cdot\left(\gamma_{S V}-\gamma_{S L}\right) \cdot \mathrm{dx}+\left(1-\phi_{S}\right) \gamma_{L V} \cdot \mathrm{dx}$

The surface roughness ' $r$ ' is constant for the grooved sidewall in this study. The surface tension between interfaces depends on the temperature of fluids which remains constant here but will be varying in an actual fuel cell gas flow channel. This theoretical correlation proves the relationship between the grooved channel wall and base surface tension differential which causes the droplet to move. The energy keeps varying and thus gives a complex, hybrid wetting behavior on the grooves. This energy gradient on the grooved surface needs to be negative (- $\mathrm{dE})$ for constant movement of the droplet on the textured or grooved surface. For that, after introducing Young's equation (equation 2), (3) becomes:

$$
\Delta \mathrm{E}=\left(\mathrm{r}-\phi_{S}\right) \cdot\left(\gamma L V \cos \theta_{E}\right) \cdot \mathrm{dx}+\left(1-\phi_{S}\right) \gamma_{L V} \cdot \mathrm{dx}
$$

For $\Delta \mathrm{E}<0$,

$$
\operatorname{Cos} \theta_{E}>\frac{1-\phi_{s}}{r-\phi_{S}}
$$


Where, $\phi_{\mathrm{s}}$ is solid fraction given by the ratio of total groove-top area to total solid area of grooved or textured surface [34]:

$\phi_{S}=\frac{\text { Groove Top's Area }}{\text { Total Area including groove tops, depths and heights }}=0.27$

On the other hand, surface roughness ' $r$ ' of a grooved pattern is given by [34]

$$
r=\frac{\text { Actual Solid Area }}{\text { Projected Solid Area }}=2.34
$$

From Eq. (5), we get:

$$
[\operatorname{Cos}(45.1)=0.7]>\left[\frac{1-0.2727}{2.34-0.2727}=0.35\right]
$$

The critical contact angle that needs to be followed by the groove designs for this energy gradient to be negative is found out by $[34,35]$ :

$$
\begin{aligned}
& \cos \theta_{C}=\frac{1-\phi s}{r-\phi s} \\
& \theta_{C}=69.35^{\circ}
\end{aligned}
$$

For the grooves implemented in this study, $\theta_{\mathrm{E}}=45.5^{\circ}$ (From Table 2) and by substituting value of $\phi s$ in equation (8), $\theta_{\mathrm{C}}=69.35$. This satisfies the condition for droplet movement condition on the sidewall based on energy gradient considerations [34,35]. Thus, the condition for negative 
energy gradient $\theta_{\mathrm{C}}>\theta_{\mathrm{E}}$ is satisfied. This confirms the wetting characteristic of the surface to avoid the static condition and encourage droplet removal from the grooved surface.

\subsection{Water Feature Movement Rate and Channel Geometry}

After completing the experimental study of all three channel wall types so far, it is crucial that the direct effect of these designs on the water feature movement and water management is quantified. This is applicable to the condition when water is generated at the channel corner which was the focus of this study. The results below are for the Configuration $\mathrm{C} 2$ when water is generated upstream in the channel and then its movement along channel length is measured. Similar work is done by Cheah et al. [11] where they studied the effect of air flow in a rectangular channel and movement of water slugs along the channel length when water droplets are produced at channel center. This section aims at identifying direct trends of the effect of changing sidewall designs on water feature dynamics in a channel. Water features (slugs and film-like features) move at a given speed due to air flow in the channel. However, their movement also depends on the surfaces in contact, their texture and contact angles. A combination of different surfaces was studied in this work. The grooved sidewalls were designed to address movement of water features along the channel length at a faster speed and provide easier ejection from channel ends. This involves eliminating slower water movement and removal in case of plain sidewalls which also causes blockages. The results below provide one to one comparison of these sidewall surfaces and its effects on water feature movement speed.

Figure $8(\mathrm{c})$ shows speeds of the slug or film-like slugs that were formed and removed from each different channel designs that were studied in this work for different superficial air 
velocities. It can be seen that there is a maximum increase in water feature speed of $38 \mathrm{~mm} / \mathrm{s}$ from the plain channel to the case of grooved channel. The change is more prominent in case of flow rates $>0.5 \mathrm{~m} / \mathrm{s}$. This data has been obtained from experiments done using the setup C2. The channel top view visualization was used to capture the dynamic water behavior using a highspeed camera. This data has been obtained in each case such that movement of water along a fixed length and time required for the same is measured.

From Figure 8(c) it is also clear that surface modifications in the form of grooves help in the drainage characteristics and help in removing water features quickly, avoiding blockage and thus accumulation. The water features that are generated are transformed and are removed at a rate quicker than the plain channel. The grooved sidewalls (one or both) help water feature movement along the channel and help drain the water generated without using higher air flow or excessive pumping power. Faster water feature movement along the sidewalls also ensures open gas diffusion layer with sufficient wetting for reactant gas transfer. These results are more significant because this channel configuration (water generation upstream) has not been studied before for water droplet emergence in a channel corner or near the sidewall. This sheds light on the way this research will be useful in fuel cell channel flow fields which consists of long channels. The effect of channel geometry and water droplet generation location along channel length is thus explored further.

\subsection{Manufacturing Considerations:}

A brief discussion is presented here to address the manufacturing considerations for making grooved sidewalls. Fuel cell channels are stamped in a metallic base plate known as bipolar plate. For fuel cells having active area $\left(>1 \mathrm{~cm}^{2}\right)$, metallic bipolar plates are made from 
Aluminum, Stainless steel, Titanium, Nickel and Carbon composites.[36] The standard method for forming solid metallic bipolar plates is machining or stamping. Stamping is the current most widely used manufacturing process, which has been the primary consideration for this work. Apart from stamping, the channel designs proposed in this study also can be manufactured by die casting and cold-forging. Considering that stamping process needs to accommodate modified process sequence to manufacture the surface modifications or grooves, the forming stage of the stamping process would be less complicated with grooves on both sidewalls of the channels. The forming dies would be easier to design and produce.

\section{Conclusions}

In this work surface modifications were applied on PEMFC channel sidewall surfaces to cause the transition of water features in the desired direction to avoid GDL wetting and better removal characteristics when water enters in a PEMFC channel under the land region. Below are the important conclusions that can be drawn from the results and discussions:

- For conventional plain trapezoidal channels (non-grooved), water droplets block and accumulate at the channel exit for velocities higher than $0.5 \mathrm{~m} / \mathrm{s}$.

- Grooved surfaces can prove useful by producing required surface energy gradient which leads to water feature transition in the desired direction at desired speeds.

- Rectangular grooves on the channel surface in a PEMFC channel helps in improving drainage characteristics by forcing formation of films which eventually produce film-like features which do not completely block the channel and hence can be removed from the channel with relative ease. 
- The channel with one grooved sidewall improves removal characteristics for low air velocities, but at higher velocities, the pinning effect of the grooves becomes prominent with slugs having film-like tails on the grooved surface. The increased hydrophilicity due to the grooves leads to the pinning effect.

- Coating the groove-tops with hydrophobic solution of Teflon helps in overcoming the pinning of the droplet on grooved surfaces in one grooved sidewall channel.

- Channels with both grooved sidewalls are a more feasible solution with manufacturing methods of these channel plates into consideration. Channels with both sidewalls having grooves do not face issues related to pinning, as the grooves on the opposite sidewall cause the motion of the films and film-like slug on the groove tops in the direction of air flow, causing easier ejection.

- Water feature removal speeds are significantly increased due to the grooved surface modifications of PEMFC channel walls.

- For cross-sectional filling identification setup, Configuration $\mathrm{C} 1$, peak pressure drops are higher by $100 \mathrm{~Pa}$ for the grooved channels than the plain channels. These peak pressure drops however concurrently reduce and stabilize after the first droplet forms, fills channel cross-section and ejects. This wasn't seen in plain sidewalls where consistent blocking of channels is observed even after first droplet forms and ejects with corresponding high peak pressure drop for each droplet.

- For flow pattern identification setup, Configuration C2, overall pressure drops are lower by $100 \mathrm{~Pa}$ for channels with grooved sidewalls than plain sidewalls as water tends to stay mainly in the film flow regime, where as plain sidewalls channel leads to formation of slugs causing higher pressure drops. 
- Both grooved sidewalls channel successfully eliminates the issue of channel blockage due to pinning of water when water is injected in the channel corner. Grooved sidewalls also avoid channel cross-sectional area blockage and GDL coverage observed in plain hydrophobic (Teflon-coated channels).

\section{Acknowledgements}

This work was conducted in the Thermal Analysis, Microfluidics, and Fuel Cell Laboratory in the Department of Mechanical Engineering at the Rochester Institute of Technology and was supported by the US Department of Energy under contract No. DE-EE0000470. The support from General Motors Electrochemistry Division at Honeoye Falls is gratefully acknowledged.

\section{REFERENCES}

[1] Kumbur, E. C., Sharp, K. V., and Mench, M. M., 2006, "Liquid droplet behavior and instability in a polymer electrolyte fuel cell flow channel," J. Power Sources, 161(1), pp. 333345 .

[2] Zijie Lu, Rath, C., Guangsheng Zhang, and Kandlikar, S. G., 2011, "Water management studies in PEM fuel cells, part IV: Effects of channel surface wettability, geometry and orientation on the two-phase flow in parallel gas channels," Int. J. Hydrog. Energy, 36(16), pp. 9864-75.

[3] Cho, S. C., Wang, Y., and Chen, K. S., 2012, "Droplet dynamics in a polymer electrolyte fuel cell gas flow channel: Forces, deformation, and detachment. I: Theoretical and numerical analyses," J. Power Sources, 206, pp. 119-128.

[4] Polverino, P., Esposito, A., and Pianese, C., 2013, "Experimental validation of a lumped model of single droplet deformation, oscillation and detachment on the GDL surface of a PEM fuel cell," Int. J. Hydrog. Energy, 38(21), pp. 8934-8953.

[5] Theodorakakos, A., Ous, T., Gavaises, M., Nouri, J. M., Nikolopoulos, N., and Yanagihara, H., 2006, "Dynamics of water droplets detached from porous surfaces of relevance to PEM fuel cells," J. Colloid Interface Sci., 300(2), pp. 673-687.

[6] Rath, C. D., and Kandlikar, S. G., 2011, "Liquid filling in a corner with a fibrous wallAn application to two-phase flow in PEM fuel cell gas channels," Colloids Surf. Physicochem. Eng. Asp., 384(1-3), pp. 653-660.

[7] Gopalan, P., and Kandlikar, S. G., 2012, "Droplet-Sidewall Dynamic Interactions in PEMFC Gas Channels,” J. Electrochem. Soc., 159(8), pp. F468-F475. 
[8] Gopalan, P., and Kandlikar, S. G., 2014, "Effect of channel materials and trapezoidal corner angles on emerging droplet behavior in Proton Exchange Membrane Fuel Cell gas channels," J. Power Sources, 248, pp. 230-238.

[9] Schneider, I. A., Dahlen, S. von, Wokaun, A., and Scherer, G. G., 2010, “A Segmented Microstructured Flow Field Approach for Submillimeter Resolved Local Current Measurement in Channel and Land Areas of a PEFC," J. Electrochem. Soc., 157(3), pp. B338-B341.

[10] Von Dahlen, S., and Schneider, I. A., 2012, "Local Flooding Phenomena in Channel and Land Areas Occurring during Dynamic Operation of a PEFC," Fuel Cells, 12(6), pp. 1004-1008. [11] Cheah, M. J., Kevrekidis, I. G., and Benziger, J. B., 2013, "Water Slug to Drop and Film Transitions in Gas-Flow Channels," Langmuir, 29(48), pp. 15122-15136.

[12] Concus, P., and Finn, R., 1994, "Capillary surfaces in a wedge: Differing contact angles," Microgravity Sci. Technol., pp. p. 152-155.

[13] Lee, S.-K., and Ito, K., 2014, "Cross-Sectional Visualization and Analysis of Droplet Behavior in Gas Flow Channel in PEFC," J. Electrochem. Soc., 161(1), pp. F58-F66.

[14] Sommers, A. D., Ying, J., and Eid, K. F., 2012, "Predicting the onset of condensate droplet departure from a vertical surface due to air flow-Applications to topographicallymodified, micro-grooved surfaces," Exp. Therm. Fluid Sci., 40, pp. 38-49.

[15] Rahman, M. A., and Jacobi, A. M., 2012, "Wetting Behavior and Drainage of Water Droplets on Microgrooved Brass Surfaces," Langmuir, 28(37), pp. 13441-13451.

[16] Baret, J.-C., Decré, M. M. J., Herminghaus, S., and Seemann, R., 2007, “Transport Dynamics in Open Microfluidic Grooves," Langmuir, 23(9), pp. 5200-5204.

[17] Seemann, R., Brinkmann, M., Herminghaus, S., Khare, K., Law, B. M., McBride, S., Kostourou, K., Gurevich, E., Bommer, S., Herrmann, C., and Michler, D., 2011, "Wetting morphologies and their transitions in grooved substrates," J. Phys. Condens. Matter, 23(18), p. 184108.

[18] Nosonovsky, M., and Bhushan, B., 2007, "Hierarchical roughness optimization for biomimetic superhydrophobic surfaces," Ultramicroscopy, 107(10-11), pp. 969-979.

[19] Liu, L., Jacobi, A. M., and Chvedov, D., 2009, "A surface embossing technique to create micro-grooves on an aluminum fin stock for drainage enhancement," J. Micromechanics Microengineering, 19(3), p. 035026.

[20] Hu, H., Huang, S., and Chen, L., 2013, "Displacement of liquid droplets on microgrooved surfaces with air flow," Exp. Therm. Fluid Sci., 49, pp. 86-93.

[21] Chen, Y., He, B., Lee, J., and Patankar, N. A., 2005, "Anisotropy in the wetting of rough surfaces," J. Colloid Interface Sci., 281(2), pp. 458-464.

[22] Gopalan, P., and Kandlikar, S. G., 2014, "Contact line characteristics of liquid-gas interfaces over grooved surfaces," Microfluid. Nanofluidics, pp. 1-10.

[23] Cassie, A. B. D., 1948, "Contact angles," Discuss. Faraday Soc., 3(0), pp. 11-16.

[24] Swain, P. S., and Lipowsky, R., 1998, "Contact Angles on Heterogeneous Surfaces: A

New Look at Cassie's and Wenzel's Laws," Langmuir, 14(23), pp. 6772-6780.

[25] "Extreme caution suggested: Superhydrophobic surfaces may have weak icephobic properties | The American Ceramic Society" [Online]. Available: http://ceramics.org/ceramictech-today/extreme-caution-suggested-superhydrophobic-surfaces-may-have-weak-icephobicproperties. [Accessed: 01-Jul-2014]. 
[26] Wang, X., Rahman, M. A., Jacobi, A. M., and Hrnjak, P. S., 2013, "Dynamic Wetting Behavior and Water Drops on Microgrooved Surfaces," Heat Transf. Eng., 34(13), pp. 10881098.

[27] Ye, D. H., Gauthier, E., Cheah, M. J., Benziger, J., and Pan, M., 2015, "The Effect of Gas Diffusion Layer Compression on Gas Bypass and Water Slug Motion in Parallel Gas Flow Channels," Aiche J., 61(1), pp. 355-367.

[28] Hellstern, T., Gauthier, E., Cheah, M. J., and Benziger, J. B., 2013, "The role of the gas diffusion layer on slug formation in gas flow channels of fuel cells," Int. J. Hydrog. Energy, 38(35), pp. 15414-15427.

[29] Lu, Z., Kandlikar, S. G., Rath, C., Grimm, M., Domigan, W., White, A. D., Hardbarger, M., Owejan, J. P., and Trabold, T. A., 2009, "Water management studies in PEM fuel cells, Part II: ex situ investigation of flow maldistribution, pressure drop and two-phase flow pattern in gas channels," Int. J. Hydrog. Energy, 34(8), pp. 3445-56.

[30] Grimm, M., See, E. J., and Kandlikar, S. G., 2012, "Modeling gas flow in PEMFC channels: Part I - Flow pattern transitions and pressure drop in a simulated ex situ channel with uniform water injection through the GDL," Int. J. Hydrog. Energy, 37(17), pp. 12489-12503.

[31] Banerjee, R., and Kandlikar, S. G., 2014, "Liquid water quantification in the cathode side gas channels of a proton exchange membrane fuel cell through two-phase flow visualization," J. Power Sources, 247, pp. 9-19.

[32] Gennes, P.-G. de, 2004, Capillarity and wetting phenomena: drops, bubbles, pearls, waves, Springer, New York.

[33] Ha, T., Kim, B., Kim, H.-S., and Min, K., 2008, "Investigation on the liquid water droplet instability in a simulated flow channel of PEM fuel cell," J. Mech. Sci. Technol., 22(5), pp. 1030-1036.

[34] Bico, J., Tordeux, C., and Quéré, D., 2001, "Rough wetting," EPL Europhys. Lett., 55(2), p. 214.

[35] Bico, J., Marzolin, C., and Quere, D., 1999, "Pearl drops," Europhys. Lett., 47(2), pp. 220-226.

[36] Spiegel, C., 2007, Designing and building fuel cells, McGraw-Hill, New York.

[37] Ye, D. H., Gauthier, E., Cheah, M. J., Benziger, J., and Pan, M., 2015, "The Effect of Gas

Diffusion Layer Compression on Gas Bypass and Water Slug Motion in Parallel Gas Flow

Channels," AICHE J., 61(1), pp. 355-367.

[38] Hellstern, T., Gauthier, E., Cheah, M. J., and Benziger, J. B., 2013, "The role of the gas diffusion layer on slug formation in gas flow channels of fuel cells," Int. J. Hydrog. Energy, 38(35), pp. 15414-15427. 
Table 2. Contact angles for different sidewall surfaces

\begin{tabular}{|c|c|c|c|}
\hline $\begin{array}{l}\text { Sr. } \\
\text { No. }\end{array}$ & Type of Channel & $\begin{array}{c}\text { CA from VCA Optima } \\
\qquad\left(^{\circ}\right)\end{array}$ & $\begin{array}{c}\text { Average CA } \\
\left({ }^{\circ}\right)\end{array}$ \\
\hline 1 & $\begin{array}{l}\text { Grooved Sidewall } \\
\text { Hydrophilic }\end{array}$ & $\begin{array}{c}48 \\
47.7 \\
44.4\end{array}$ & 45.5 \\
\hline 2 & $\begin{array}{l}\text { Non-grooved Sidewall } \\
\text { Hydrophilic }\end{array}$ & $\begin{array}{l}49.2 \\
54.4 \\
51.3\end{array}$ & 51.8 \\
\hline 3 & $\begin{array}{l}\text { Grooved Sidewall } \\
\text { Hydrophobic }\end{array}$ & $\begin{array}{l}114.5 \\
108.5 \\
97.2\end{array}$ & 103.8 \\
\hline
\end{tabular}




\section{LIST OF FIGURES}

Fig. 1. Experimental Setup for Visualizing Droplet-Sidewall Interaction, (a) Channel geometry, (b) Configuration $\mathrm{C} 1$, (c) Configuration $\mathrm{C} 2$.

Fig. 2. Droplet-sidewall Interaction, Plain Trapezoidal Channel, 0.5 m/s (Config. C1).

Fig. 3. (a) Plain Sidewalls Channel, Config. C1.1 - Pressure Drop for Low Air Velocities (Low air velocities) (1) $0.18 \mathrm{~m} / \mathrm{s}$ (2) $0.36 \mathrm{~m} / \mathrm{s}$; (b) Plain Sidewalls Channel- Pressure Drop for High Air Velocities (High air velocities) (1) $0.7 \mathrm{~m} / \mathrm{s}$ (2) $0.8 \mathrm{~m} / \mathrm{s}$.

Fig. 4 (a) First Slug Formation and Removal for Air Velocities $>0.5 \mathrm{~m} / \mathrm{s}$; (b) Droplet Sticking Phenomenon for Air Velocities > $0.5 \mathrm{~m} / \mathrm{s}$ (Config. C1 Plain Channels).

Fig 5. Image sequences before and just after slug ejection- (a) Plain Sidewalls, C1.1, (b) Single Grooved sidewall, C1.2, (c) Both grooved sidewalls, C1.3 - Air velocity $0.5 \mathrm{~m} / \mathrm{s}$, Water flow rate $0.05 \mathrm{ml} / \mathrm{min}$ (Configuration C1); Cross-Sectional Channel Area Blockage Illustration (d) Water Partially Occupying the Channel (Config. C1).

Fig. 6 (a) Pressure Drop Signatures for: 1. Plain Channels (C1.1), 2. One Grooved Sidewall (C1.2a), (3) Teflon Coating only on groove-tops(C1.2b), (4) Both grooved sidewalls. (C1.3); (b) Droplet Accumulation and Blockage after Slug 1 exits the channel- One Grooved Sidewall (C1.2 a); (c) Droplet Accumulation and Blockage after Slug 1 exits the channel- One Grooved Sidewall (C1.2b), Effect of Teflon Coating 
Fig. 7 (a) 1. Pressure drop signatures - Water entry upstream C2- plain sidewall channel (C2.1a) and (a) 2. Both grooved sidewalls (C2.2a); (b) Plain sidewalls channel- water feature size and shape transition - 1. upstream to ejection (C2.1a), 2. Both Grooved Sidewalls (C2.3).

Fig. 8. Peak pressure drop- All channel designs and air flow velocities (a) water injection near channel exit, (C1), (b) water injection upstream, (C2); (c) Water feature motion speeds for C2.1, $\mathrm{C} 2.2$ and $\mathrm{C} 2.3$.

\section{Figure 1}

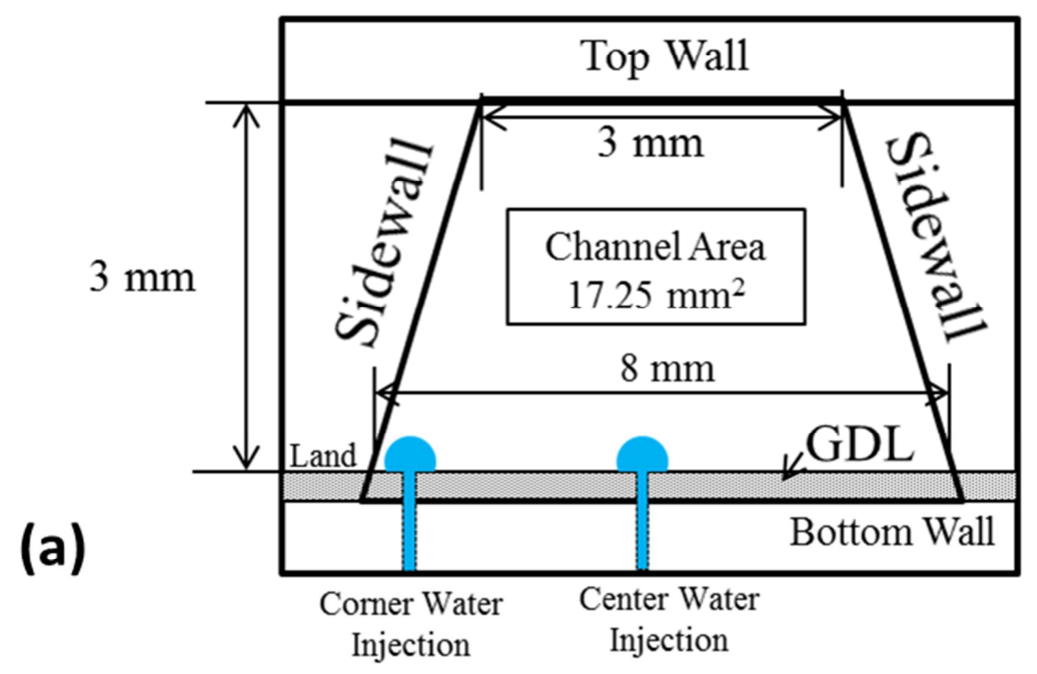




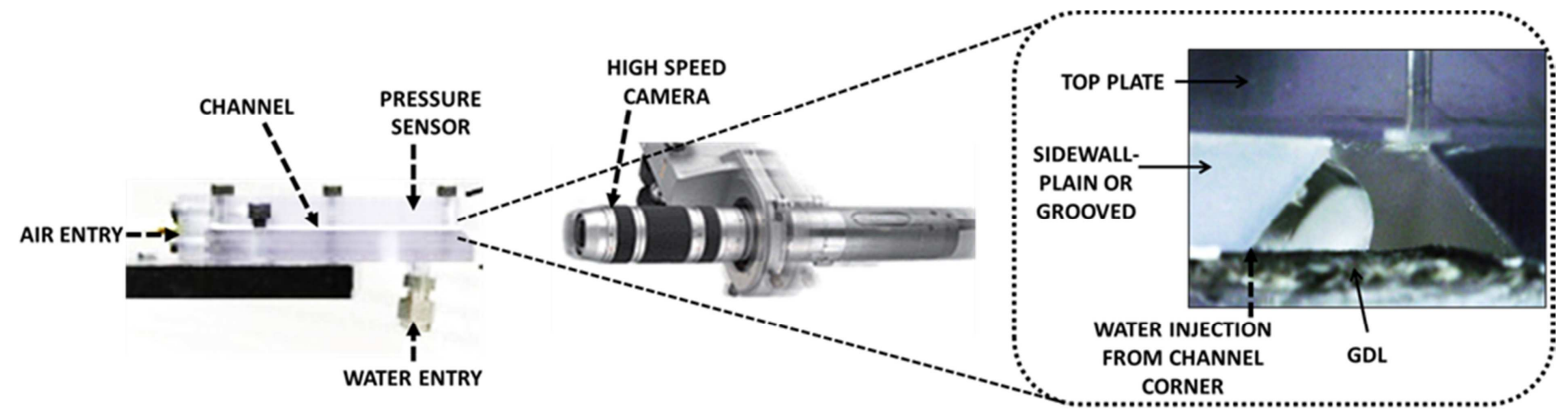

(b)

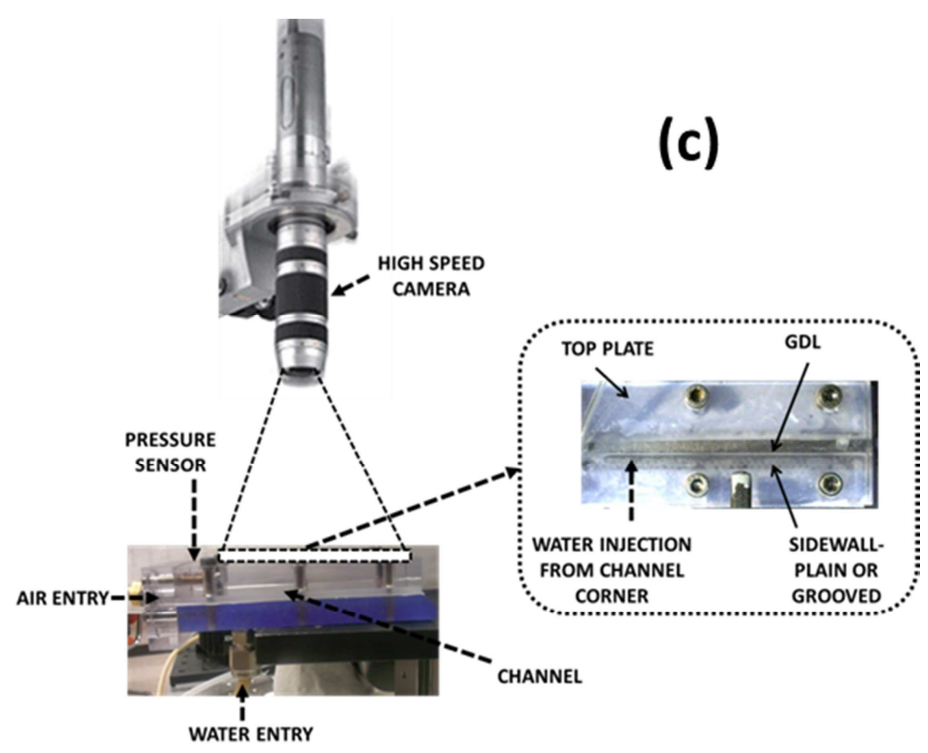


Figure 2

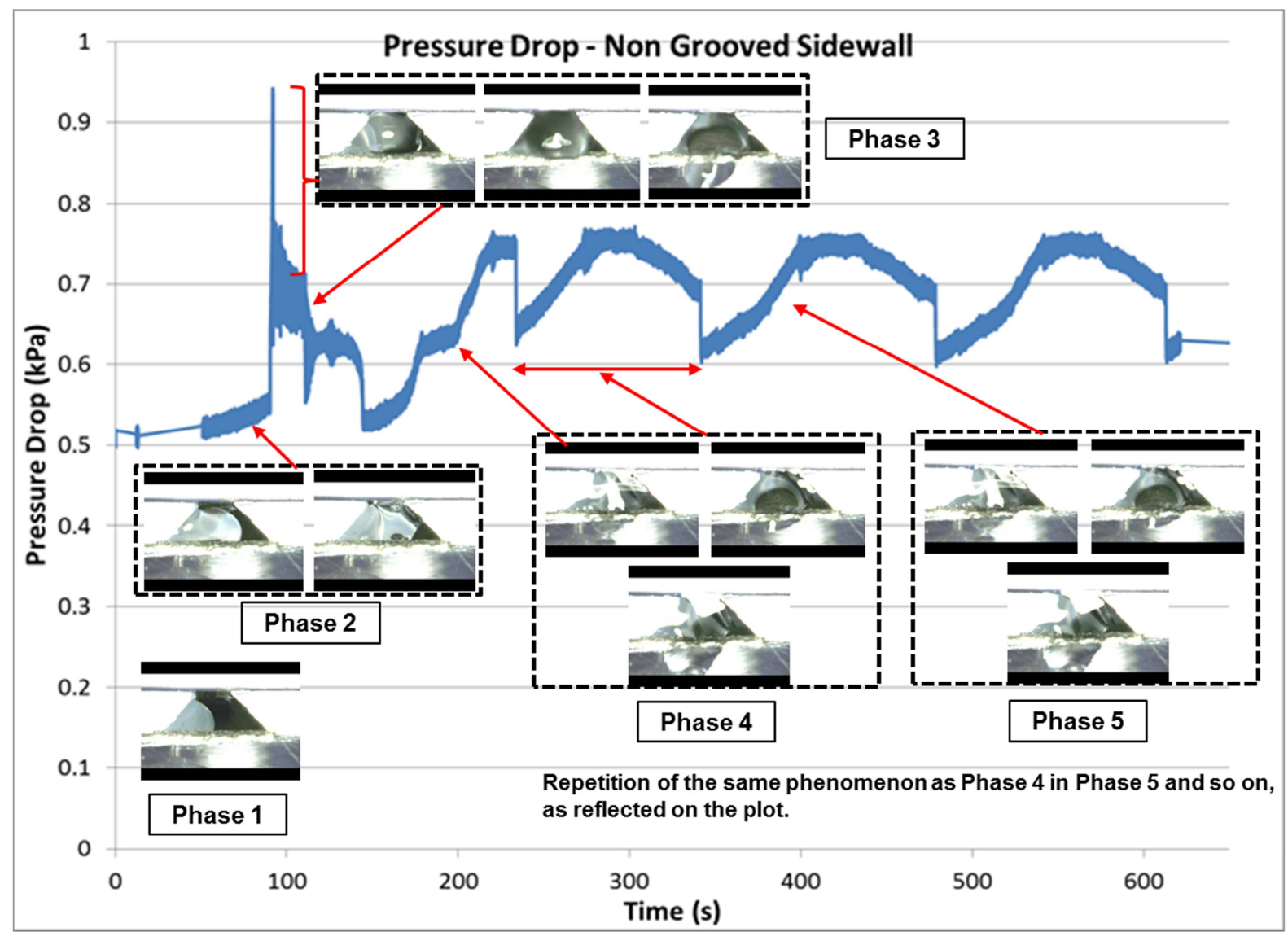




\section{Figure 3}
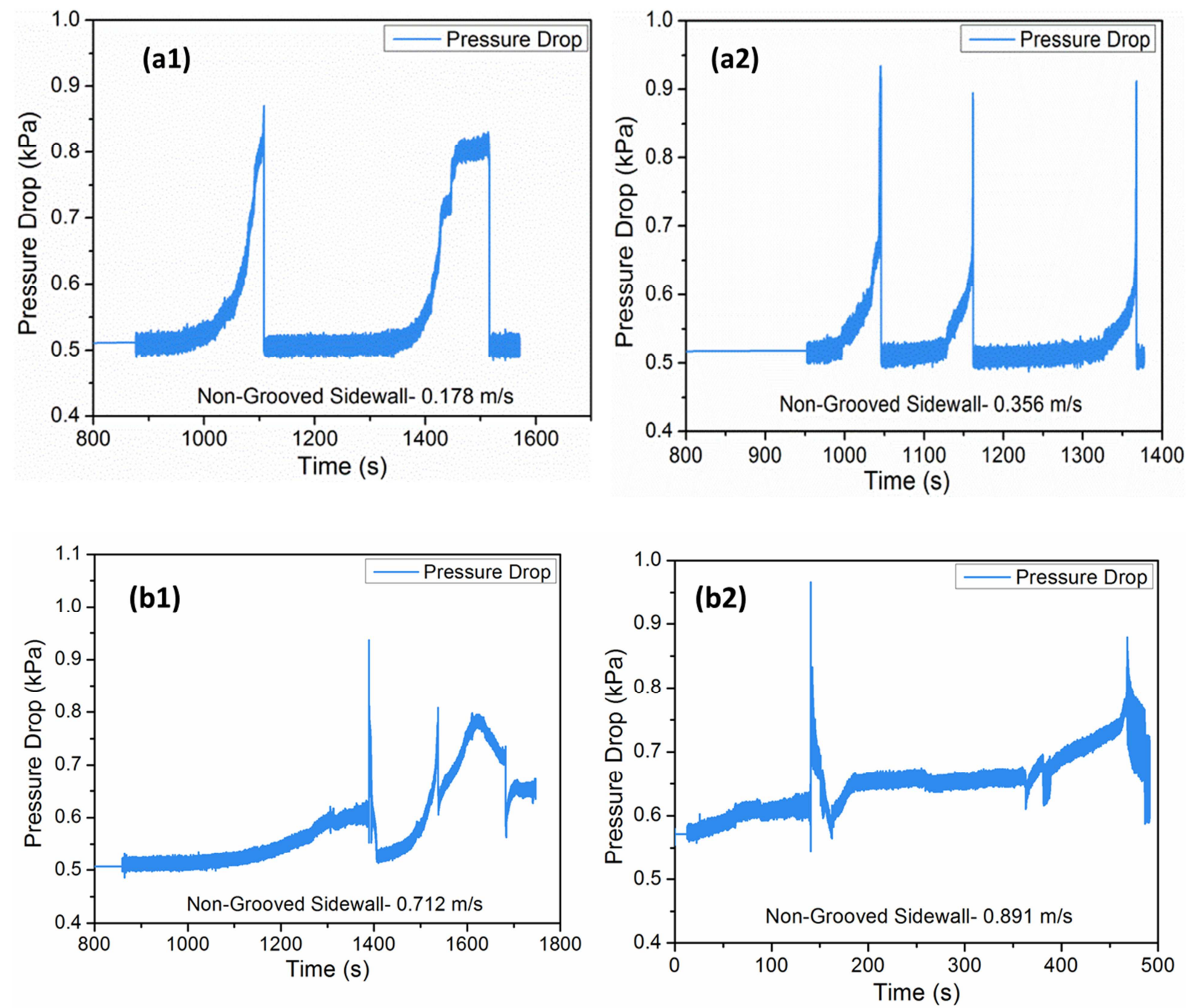
Figure 4

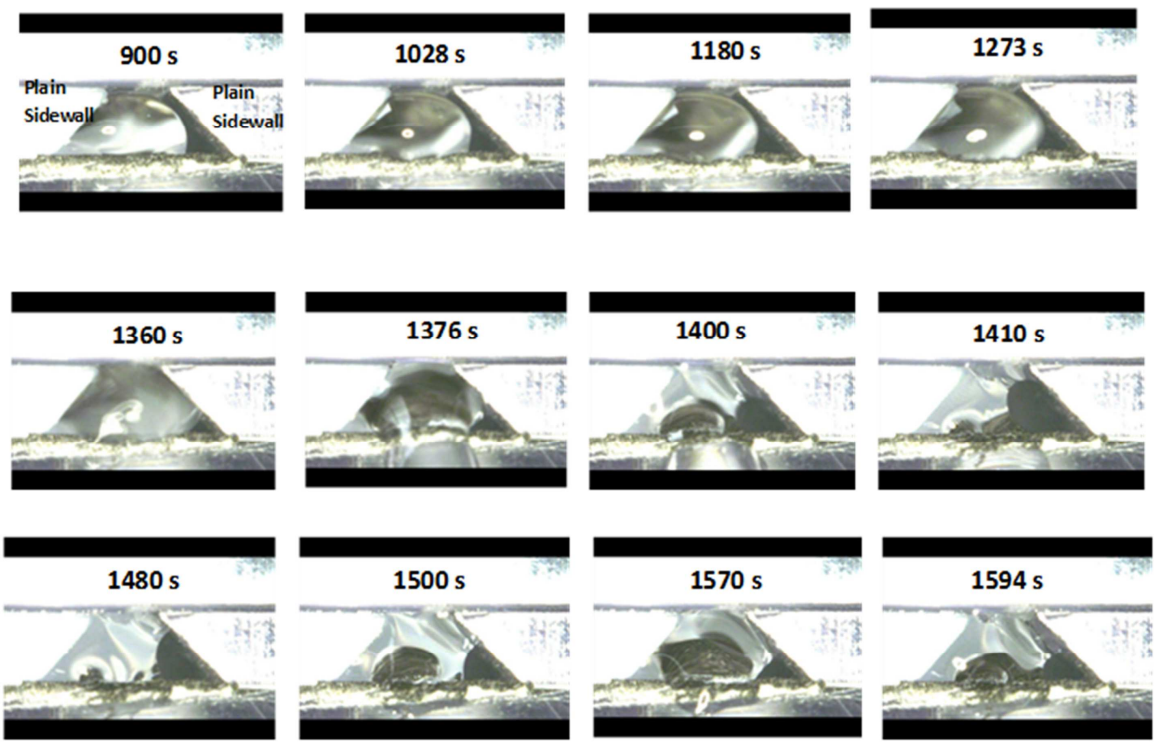

(a)

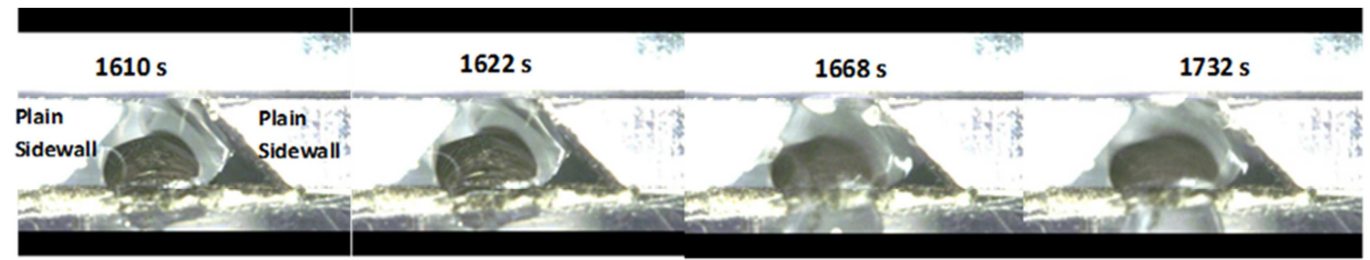

(b) 
Figure 5 

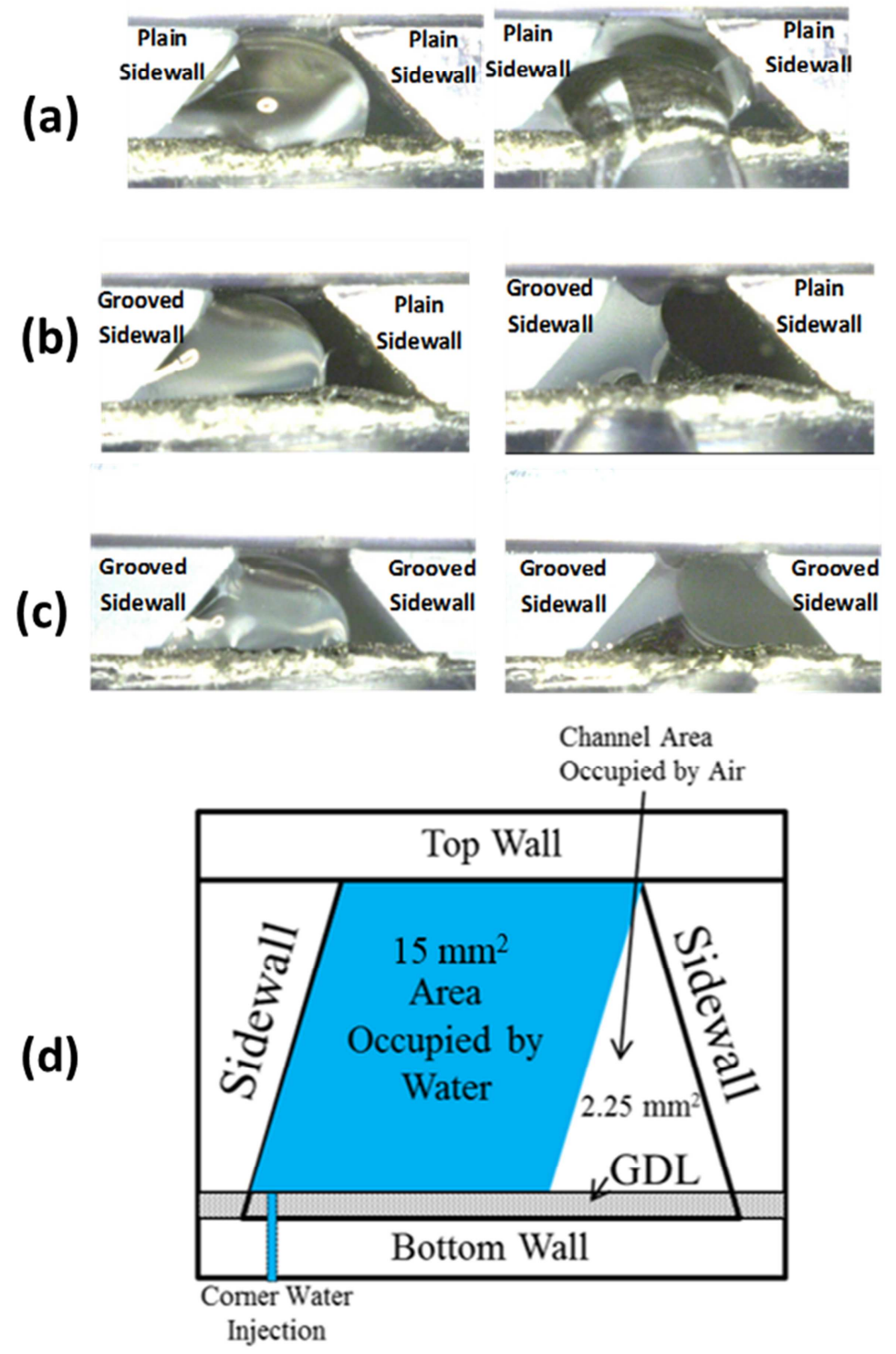
Figure 6
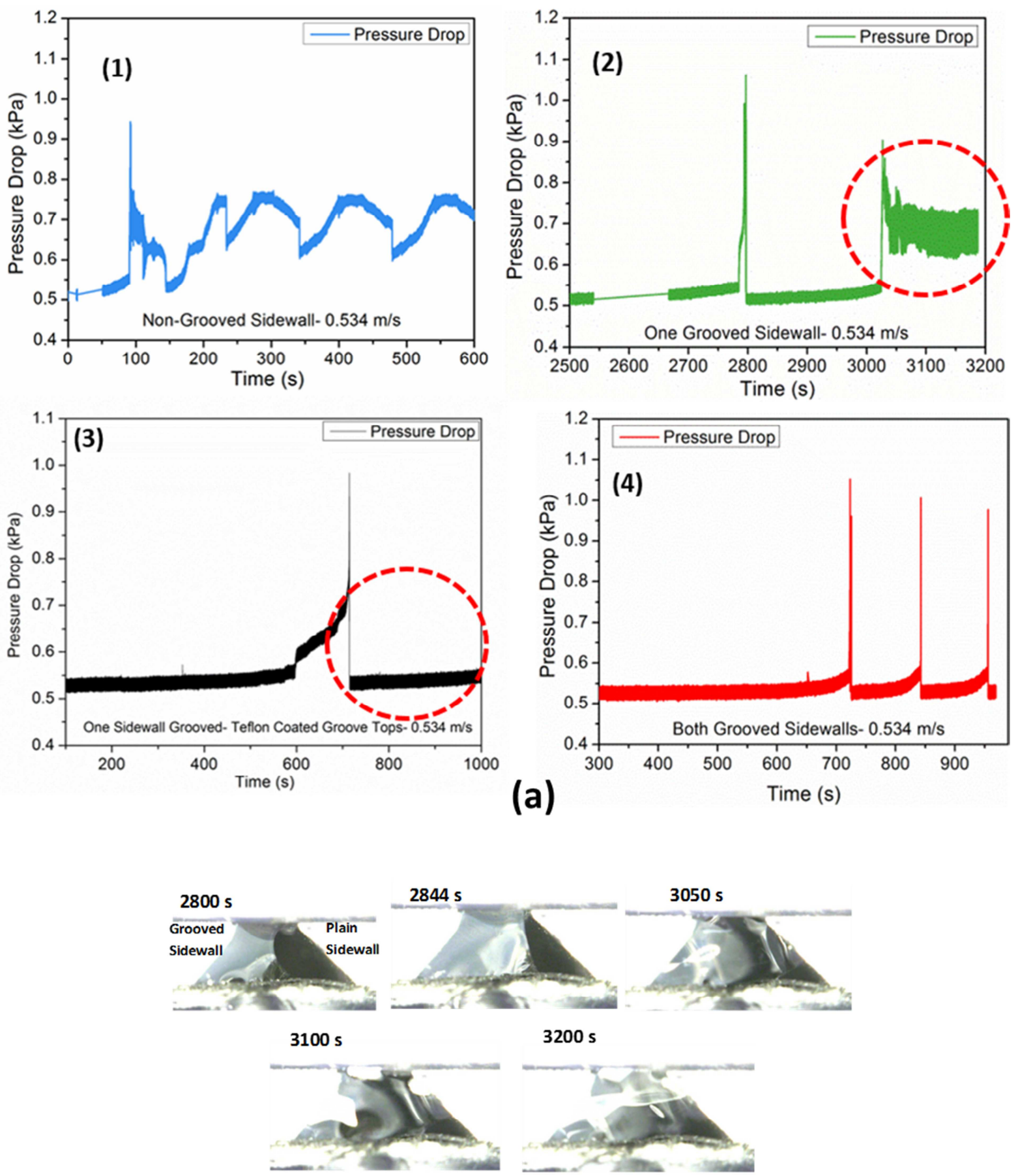

(b) 

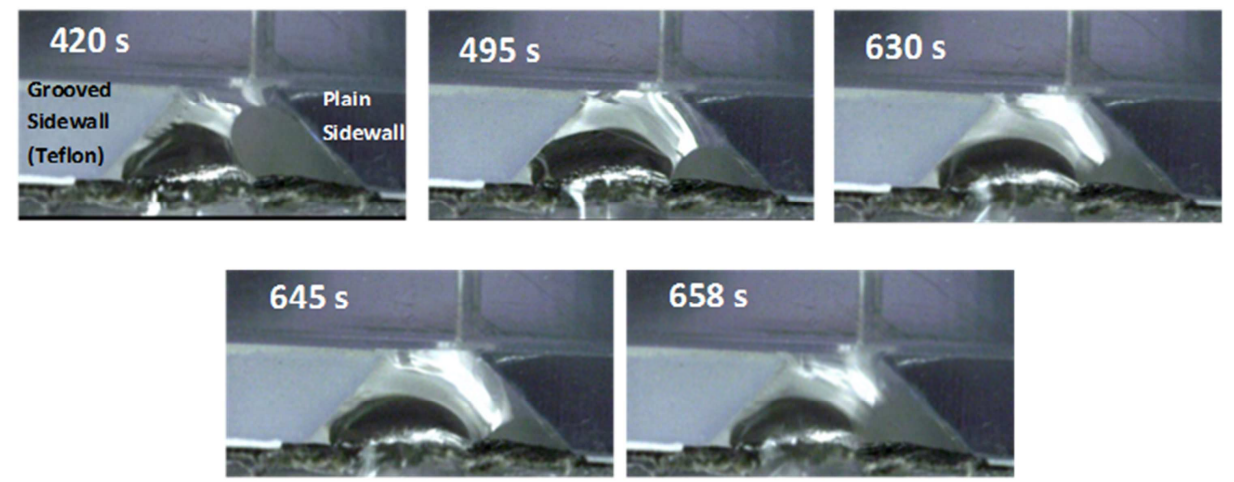

(c) 
Figure 7
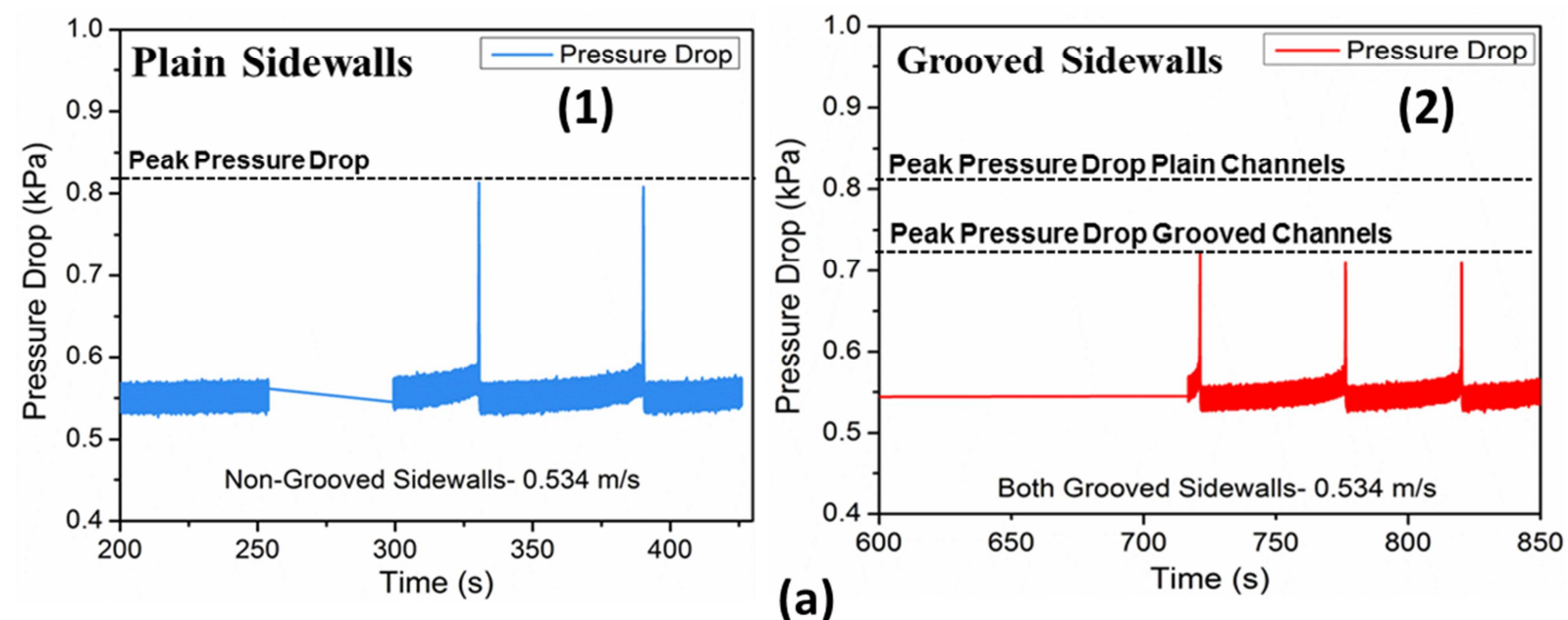


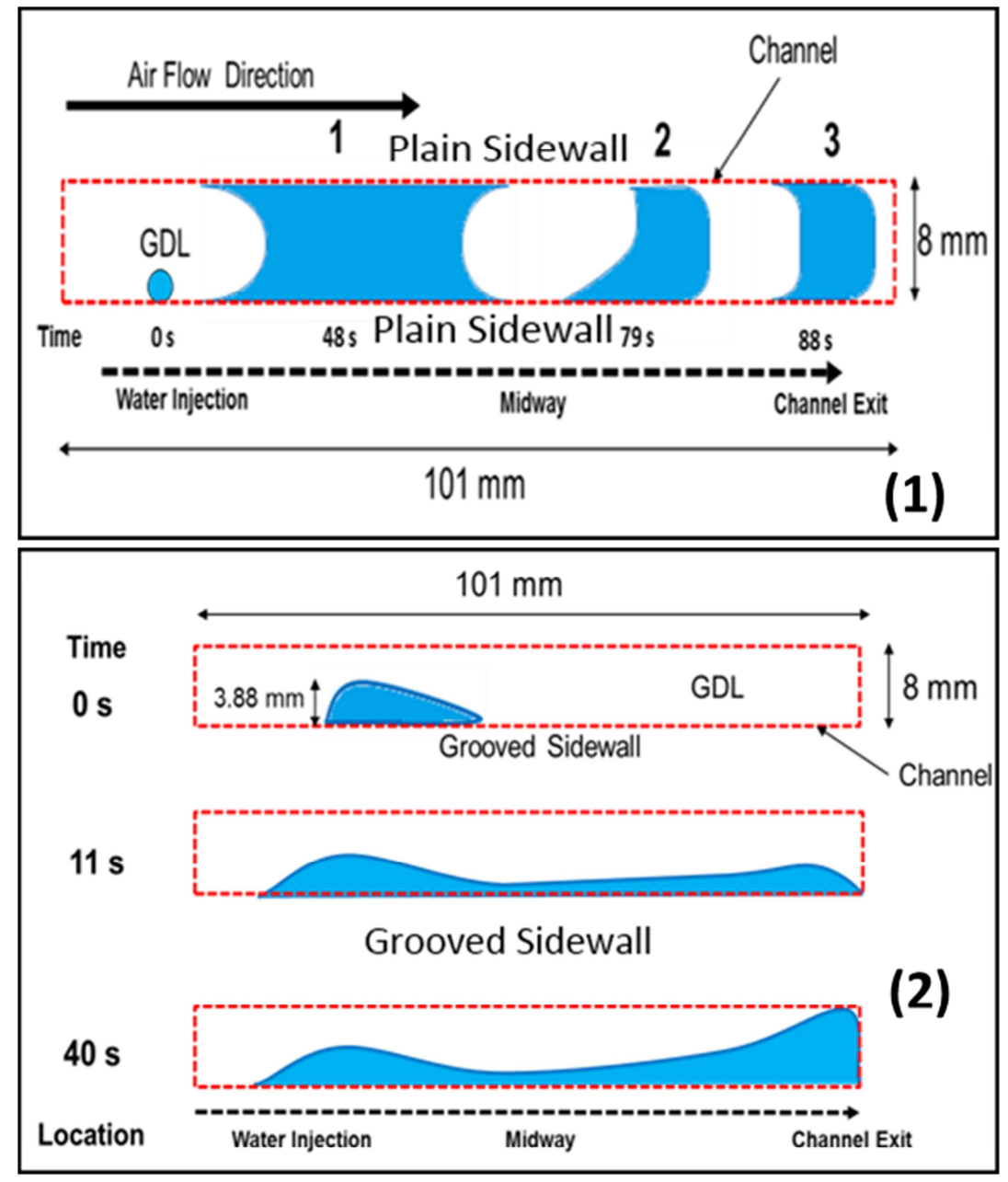

(b) 
Figure 8
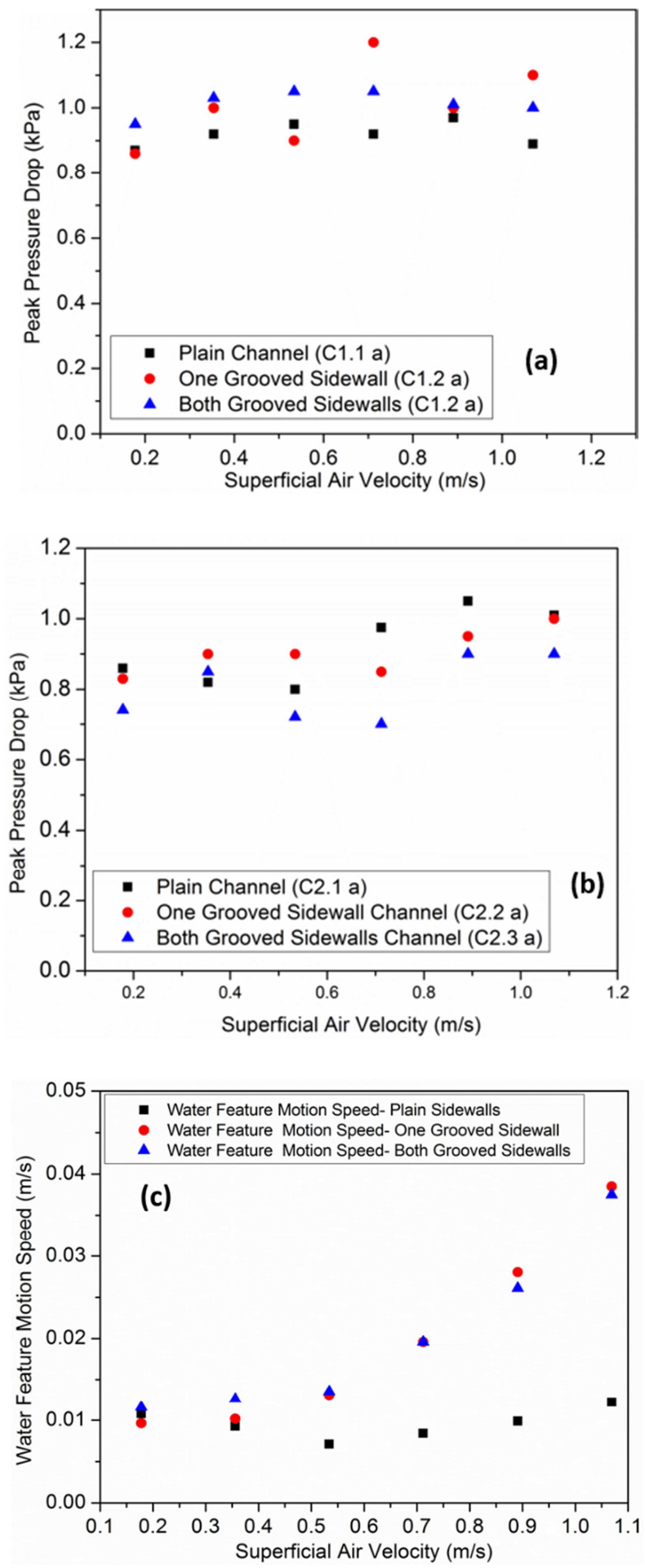
Table 1: Operating Flow Conditions used for Testing

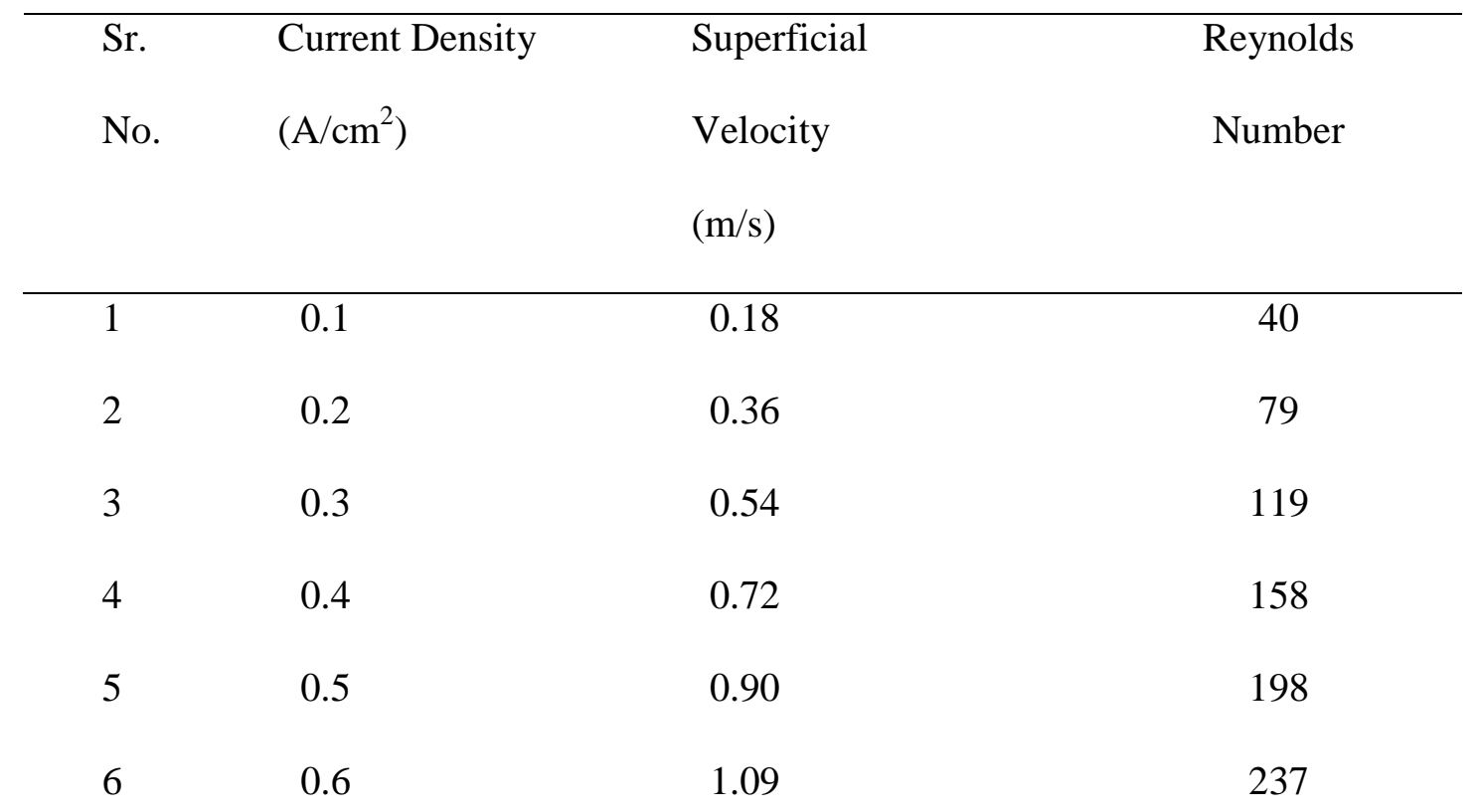

